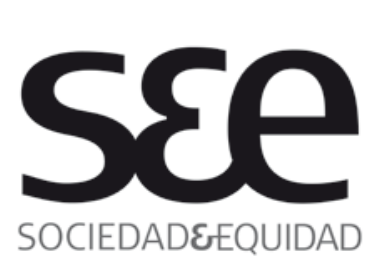

\title{
Reseña: Encuentros disciplinarios y debates metodológicos. La práctica de la investigación sobre migraciones y movilidades $(*)$
}

Disciplinary meetings and methodological debates. The research practice on migration and mobility

Nombre:

Filiación:

País:

Correo:

\author{
Florencia J ensen Solivellas ${ }^{(*)}$ \\ Universidad de Buenos Aires \\ Argentina \\ florenciajensen@gmail.com
}

\section{Resumen}

Se comenta el libro 'Encuentros disciplinarios y debates metodológicos. La práctica de la investigación sobre migraciones y movilidades' en relación a dos ejes fundamentales: la metodología en el proceso de investigación y la reflexividad que permite el campo. La problematización de las diversas técnicas y la necesidad de contar con equipos multidisciplinarios que requiere el fenómeno migratorio es lo que se destaca de la compilación. La lectura crítica de cada uno de los capítulos permite comprender la trastienda de una investigación.

\section{Palabras Claves}

Migraciones, Movilidad, Metodología, Multidisciplinariedad.

(*)L. Rivera Sánchez y F. Lozano Ascensio (coordinadores). 2009. Colección Desarrollo y Migración. Centro Regional de Investigaciones Multidisciplinarias. Universidad Autónoma de México.

(*) La autora es Dra @ en Ciencias Sociales - UBA Magíster Antropología y Desarrollo (U. Chile) y Socióloga (UBA). Sus líneas de investigación son: migraciones latinoamericanas, subjetividad migrante, identidad y Procesos de reconfiguración identitarios, integración de los migrantes y políticas migratorias. 


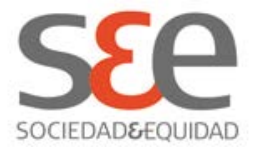

\begin{abstract}
The book's Disciplinary Encounters and methodological debates" is reviewed The research practice on migration and mobility 'in relation to two key areas: the methodology in the research process and reflexivity that enables the field. The problematization of various techniques and the need for multidisciplinary teams required by the migration phenomenon is what stands out in this compilation. A Critical reading of each of the chapters enables a deeper understanding of investigations.
\end{abstract}

\title{
Keywords
}

Migration, Mobility, Methodology, Multidisciplinary.

Resulta interesante $\mathrm{y}$, sobre todo, académicamente relevante encontrar un libro que reflexione sobre el quehacer de la investigación en los estudios migratorios. En primer lugar, porque no se trata de una práctica recurrente $y$, en segundo lugar, porque alienta a quiénes están(mos) en plena cocina investigativa, tanto a la reflexión metodológica como al buen "cuestionamiento" de la práctica y el lugar que ocupa el investigador en todo el proceso. Con todo ello nos encontramos en el libro titulado "Encuentros disciplinarios y debates metodológicos. La práctica de la investigación sobre migraciones y movilidades" que coordina Rivera Sánchez y Lozano. Editado en el año 2009, el libro se centra en el debate y reflexión de la experiencia metodológica de equipos multidisciplinares especializados en estudios migratorios y de movilidad. El libro recorre a través de sus siete capítulos, las experiencias de estos equipos de investigación, discutiendo los avances y retrocesos de las investigaciones, así como los instrumentos y herramientas utilizados en sus estudios.

Podríamos mencionar como logro del libro que a lo largo de los capítulos, se evidencia la articulación de las distintas reflexiones metodológicas de investigadores provenientes no sólo de diversas disciplinas sino también de ubicaciones locales/geográficas variadas. Ello permite la emergencia de lecturas contrapuestas a la vez que complementarias, para abordar la multiplicidad de aristas que componen o pueden llegar a componer los análisis en los estudios de los fenómenos migratorios y de la movilidad humana. 


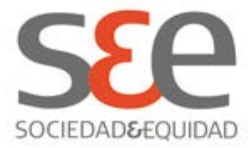

Estas reflexiones habilitan al lector dos puntos centrales. Por un lado, conocer la 'cocina' de un proyecto de investigación (ya en marcha o por comenzar), los debates, avances y retrocesos del mismo, los errores o traspiés que obligan a la toma de nuevas decisiones, las discusiones disciplinares. $Y$, por el otro, el conocimiento del campo y de las metodologías para su abordaje.

El libro es el resultante de un seminario de carácter internacional y multidisciplinario que se orientó a generar un espacio de diálogo entre académicos de diferentes orígenes. El mismo se llevó a cabo en el año 2006 en la Universidad Autónoma de México, con otros dos encuentros en los años subsiguientes (2007 y 2008). Los productos finales de esos seminarios son los artículos que integran la compilación.

La publicación de este libro invita a la lectura de todos aquellos que trabajan(mos) sobre los fenómenos migratorios actuales y, como tal, irrumpe en el contenido la pregunta por el acercamiento entre las diversas culturas, a la vez que pone en cuestión algunas de las categorías metodológicas de las ciencias sociales en general y de la antropología clásica en particular. Cuando se aborda el estudio de las migraciones y las movilidades humanas, el trabajo de campo ya no se produce en un terreno ajeno a la propia vida del investigador, sino que nativo e investigador comparten el mismo espacio. En este marco, la compilación interroga respecto a la utilidad de ciertas técnicas y herramientas metodológicas, la proposición de otras novedosas y los resabios heredados de las visiones más positivistas del trabajo etnográfico.

En este sentido, el libro sostiene la reflexividad como condición necesaria en la producción del conocimiento. Así, a lo largo de los siete capítulos, podemos observar como éste supuesto fundamental en la investigación estuvo presente en todos los proyectos de investigación. La importancia tanto de la flexibilidad como de la reflexividad, recomendable asumir en un contexto de trabajo de campo, es lo que permite avanzar y retroceder en dicho proceso, pudiendo así reflexionar sobre nuestras propias prácticas, articulándolas con las pre-nociones y bagajes de teorías previas.

En el campo de la investigación migratoria, el libro "Encuentros disciplinarios y debates metodológicos. La práctica de la investigación sobre migraciones y movilidades" resulta una muy buena guía para quienes trabajamos en el ámbito de las temáticas migratorias 0 , mejor, para quienes trabajamos e investigamos sobre "sujetos migrantes". El libro permite comprender que no existe una sola teoría coherente y unificada de las migraciones internacionales, sino una serie de teorías y diferentes concepciones metodológicas que se han ido desarrollando en gran medida de forma aislada unas de otras. 


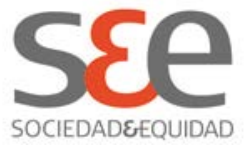

A lo largo del libro, las experiencias de investigaciones interdisciplinarias que se rescatan, en la articulación y complementariedad de sus perspectivas, en el propio proceso de investigación con la premisa de la reflexividad, adquieren la permeabilidad de sus fronteras para así contribuir a la construcción de categorías analíticas y conceptuales que respondan a dicho proceso; al tiempo que permiten abordar la complejidad de la realidad social.

Los artículos del libro recorren las dificultades y obstáculos teóricos, epistemológicos y metodológicos que atraviesan diferentes equipos de trabajo en el proceso de investigación. Pensar el trabajo de campo como una instancia reflexiva del conocimiento, permite pensar cómo se va construyendo de manera dialéctica el conocimiento a partir de la relación entre investigador e informante.

El acceso al campo no es neutro y el conocimiento del mundo social que el investigador intenta desentrañar no se puede alcanzar sin pensar a éste como un mundo ya interpretado por los actores sociales, por tanto, lo que allí se pone de manifiesto es la relación entre ambos sujetos (Guber, 2009). Asimismo, los datos no hablan por sí solos, sino que lo hacen a la luz de determinados supuestos teóricos lo que queda explícito en los debates que aparecen en los capítulos del libro. En este sentido existen distintas aproximaciones al estudio de las migraciones internacionales: la teoría económica, la aproximación histórica estructural o la teoría de sistemas de las migraciones, entre otras.

En esta línea, el capítulo 3 de Ariza, plantea que no son pocos los usos y abordajes analíticos que han empezado a cuestionar los estudios migratorios desde la última década del siglo pasado, produciendo una ruptura con la dicotomía origen-destino como forma consagrada de abordar la movilidad espacial y su sustitución por la idea de continuidad o fluidez entre los espacios sociales a los que permanentemente enlaza la migración, vistos ahora como trasnacionales. Más específicamente, interesa rescatar la experiencia total del migrante, dado que ésta influye sustancialmente en su inserción en la sociedad de destino, al tiempo que impacta en su relación con la sociedad de origen y su propia trayectoria de vida como migrante.

La propuesta metodológica que se propone en el texto se centra en el análisis de las experiencias migratorias en un contexto histórico y espaciotemporal específico, entendiendo que ésta se produce en el entrecruce entre una vivencia subjetiva del ser migrante, del desarraigo y del impacto de fuerzas y contextos sociales, políticos, culturales y económicos en los que tiene lugar la migración y los procesos de integración local. En ese sentido el capítulo de Ariza (Cf. Capítulo 3) plantea que el análisis no debe agotarse en la población migrante, sino que incluye a los diversos factores que median en las relaciones 


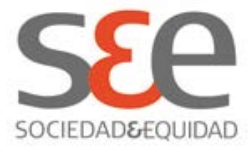

que estas personas mantienen con el nuevo entorno. Teniendo en cuenta las particularidades de la situación de determinados sujetos migrantes, el capítulo de Ariza recomienda otorgar prioridad a los métodos cualitativos sobre los cuantitativos, dado que se trata de una población de difícil acceso y con elevados porcentajes de subregistro en los datos oficiales.

En consonancia con lo anterior, resulta interesante la conceptualización que realizan Riaño Alcalá y Villa Martínez (Cf. Capítulo 4) de "trayecto migratorio", al cual definen como la suma de recursos económicos, sociales y culturales con los que cuentan las personas en el transcurso del proceso migratorio, la manera en cómo disponen de ellos y cómo interactúan con otros factores tanto del contexto de origen como receptor. En suma, estos aspectos definen las características de la migración y el modo en cómo ésta se organiza y explican las diferencias y contrastes entre las modalidades de migraciones forzada y la experiencia de los individuos. Esta información suplementaria es la que nos permite desarrollar el proceso de reflexividad, dando cuenta de nuestros pre-conceptos, ampliando la mirada del fenómeno y de las estrategias metodológicas para abordarlo.

En relación con las decisiones metodológicas que el trabajo requiere, coincidimos en la elección de una estrategia metodológica constructivista del dato, a lo largo del proceso de investigación, en el sentido de ir elaborando y generando paulatinamente nuevos datos en cada fase. La lectura que realizan Rivera y Lozano, (Cf. Capítulo 6) brinda herramientas para pensar este proceso, dado que entienden que hay dos formas distintas de construir el dato: una es como usualmente se hace en las ciencias básicas, como cierta información o hallazgo empírico que tiene un referente en la realidad (más cercano a las ideas positivistas), sería el dato de primer orden, reconociendo que también es una construcción. La segunda forma de entenderlo es producto del ejercicio de filtrar la primera evidencia obtenida a través del análisis elaborado con el andamiaje conceptual y metodológico, lo que denominan como dato complejo 0 de segundo orden.

Otro recurso metodológico que tiene gran potencial y que es rescatado en la compilación, es el método de la comparación (cf. Capítulo 3). Se utiliza para la sistematización de los rasgos de los distintos fenómenos observados con la finalidad de encontrar regularidades especialmente cuando se cuenta con pocos casos de observación. Este recurso se basa en una serie de supuestos y procedimientos encaminados a asegurar la validez de las inferencias, entre los que sobresalen la sistematización del contexto de comparación y el carácter controlado de la contrastación. 


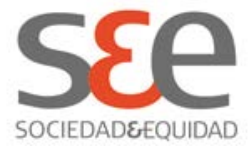

Rescatamos la complementariedad de las miradas disciplinarias para estudiar las migraciones que plantea la compilación mencionada, debido, fundamentalmente, a la necesidad de conocer las trayectorias como un conjunto. En este sentido, retomamos de la Sociología la dinámica de las instituciones, sean éstas el Estado o las familias, ya que son claves para entender procesos de cambio social y el papel de los actores en estos. Desde la Antropología, por su parte, la construcción social de las identidades, como la dimensión social fundamental para examinar la agencia social y política de los actores y la relevancia de la perspectiva histórica como entrada para comprender las dinámicas sociales presentes.

Por último, advertimos que si bien la intención del libro fue poner en discusión los diversos abordajes metodológicos, le cuesta escapar a la enquistada tradición que tienen en el marco de los estudios migratorios la perspectiva "Norte-sur", tanto en las temáticas de los artículos como también en la localización y procedencia de los investigadores. Los colaboradores de la compilación (y participantes del seminario) en su mayoría son académicos localizados en el continente americano, fundamentalmente estudiosos de las migraciones latinoamericanas en Estados Unidos. Y, en efecto, hay un vacío de artículo en torno a temáticas de movilidades y migraciones de las cada vez más presentes migraciones Sur-sur.

En suma, la compilación presenta por un lado las reflexiones en torno a la investigación, al campo en concreto a la vez que reflexiones ligadas al método pertinente para cada investigación. La lectura del libro nos permite acceder a la trastienda de la investigación, reflexionar en torno a la trayectoria, cuáles fueron las decisiones que se tomaron en el transcurso de la misma, así como también los cambios de rumbos que el campo muchas veces obliga a tomar. Por lo tanto, presentar al lector crítico los ajustes, cambios, avances y retrocesos de una investigación permite presentar a la misma (independientemente de si se trata de una investigación cualitativa o cuantitativa) ya no como un resultado cerrado que fue planificado y ejecutado sin tomar en cuenta los condicionantes internas y externas, sino como el trabajo en equipo y la permanente vigilancia epistemológica que toda investigación requiere. Sin dudas, el aporte se vincula con despojarse de los residuos de positivismo que, incluso actualmente, emergen en muchas investigaciones y, sobre todo, en los requisitos de publicación. 


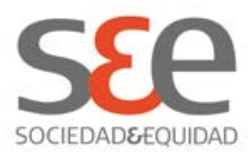

\section{Referencias Bibliográficas}

Lozano Ascencio, F (Coord) (2009). Encuentros disciplinarios y debates metodológicos. La práctica de la investigación sobre migraciones y movilidades. Universidad Nacional de México. DF, México.

Guber, R. (2001). La etnografía, método, campo y reflexividad. Grupo Editorial Norma, Bogotá.

Guber, R. (2009). El salvaje metropolitano. Reconstrucción del conocimiento social en el trabajo de campo. Paidós. Buenos Aires. 